\section{Hemophagocytic Lymphohistiocytosis Secondary to Mycoplasma Pneumoniae Infection in a Trisomy 21 girl}

DOI: 10.1515/rrlm-2017-0039

\section{Dear Editor,}

Hemophagocytic lymphohistiocytosis (HLH) is a rare life-threatening disorder characterized by persistent fever, splenomegaly, cytopenia, hypertriglyceridemia and hypofibrinogenemia. There are two major forms described: primary $\mathrm{HLH}$, which includes familial hemophagocytic lymphohistiocytosis (FHL) and several primary immunodeficiencies (Griscelli syndrome, Chediak-Higashi syndrome, X-linked lymphoproliferative syndrome, Hermansky-Pudlak syndrome type II, X-linked hypogammaglobulinemia, Wiskott-Aldrich syndrome and DiGeorge syndrome), and secondary HLH that is associated with infections (viral, bacterial, parasitic or fungal), autoimmune disorders (systemic juvenile idiopathic arthritis, lupus erythematosus, polyarteritis nodosa, sarcoidosis, systemic sclerosis, periodic fever syndromes, Kawasaki syndrome and Sjögren's syndrome), malignancies (acute B-lymphoblastic leukemia, lymphoma, neuroblastoma, rhabdomyosarcoma), metabolic diseases (Gaucher disease, lysinuric protein intolerance) and following immunosuppressive therapy and organ and stem cell transplantation (1-3). There are studies that have suggested that HLH represents the combined effects of genetic predisposition and an exogenous trigger factor (4). Diagnostic guidelines were established in 2004 by the Histiocyte Society and require at least five of the following eight criteria: fever, splenomegaly, cytopenia affecting at least two cell lines, hyperferritin- emia, hypertriglyceridemia and/or hypofibrinogenemia, hemophagocytosis in the bone marrow, spleen, liver or lymph nodes, elevated levels of soluble IL-2 receptor and low or absent natural killer (NK) cell activity (5). Treatment of HLH involves immunosuppressive therapy, biological response modifiers, treatment of the underlying disease and hematopoietic stem cell transplantation $(1-3,5)$.

Here, we report a 10-year-old girl with trisomy 21 and cardiac malformation (complete atrioventricular canal defect and pulmonary hypertension) who was diagnosed with HLH-associated Mycoplasma pneumoniae. Informed consent for this presentation was obtained from the girl's guardians. The patient was admitted to our clinic in April 2016 for persistent fever, coughing, dyspnea and cyanosis despite initial treatment with i.v. cefuroxime for five days during hospitalization at another pediatric clinic for bacterial pneumonia. Physical examinations revealed characteristic dysmorphic features for trisomy 21, cyanosis, tachycardia (120 bpm), systolic murmur, accentuated second heart sound and mild hepatosplenomegaly. Chest auscultation exhibited bilateral lung crackles. Chest radiography indicated bilateral pulmonary hilum infiltrates and bulging of the pulmonary artery (the latter a marker for pulmonary hypertension). Laboratory findings revealed: red blood cell (RBC) counts at $3.33 \times 10 \mathrm{e} 12 / \mathrm{L}$, hemoglobin $(\mathrm{Hb})$ at $10.9 \mathrm{~g} /$ $\mathrm{dL}$, hematocrit $(\mathrm{Ht})$ at $33.7 \%$, white blood cell (WBC) counts at $5.5 \times 10 \mathrm{e} 9 / \mathrm{L}$ with $79 \%$ neutrophils, 17\% lymphocytes and 4\% monocytes, platelet (Plt) counts at 6x10e9/L, lactate dehydrogenase (LDH) at $1163 \mathrm{IU} / \mathrm{L}$, triglyceride (TG) at $433 \mathrm{mg} / \mathrm{dL}$, ferritin $>1500 \mu \mathrm{g} / \mathrm{L}$, C-reactive protein (CRP) at $99 \mathrm{mg} / \mathrm{L}$, erythrocyte sedimentation rate $(\mathrm{ESR})$ at $68 \mathrm{~mm} /$ hour, aspartate ami- 
notransferase (AST) at $115 \mathrm{IU} / \mathrm{L}$, alanine aminotransferase (ALT) at $52 \mathrm{IU} / \mathrm{L}$, immunoglobu$\operatorname{lin}(\mathrm{Ig}) \mathrm{G}$ at $18.38 \mathrm{~g} / \mathrm{L}, \operatorname{IgA}$ at $2.37 \mathrm{~g} / \mathrm{L}$ and $\operatorname{IgM}$ at $3.09 \mathrm{~g} / \mathrm{L}$. Serological tests for Epstein-Barr virus, cytomegalovirus, Parvovirus B19 (IgM determination using the immunofluorescence assay) and hepatitis $B$ virus, hepatitis $\mathrm{C}$ virus and HIV (determined by electrochemiluminescence method) were negative. Blood cultures were negative. Quantiferon testing was also negative. Bone marrow aspiration from the posterior iliac crest demonstrated a normocellular marrow with granulocytic hyperplasia, erythroid hypoplasia at the predominantly proerythroblast stage and rare macrophages with hemophagocytosis (figure 1). Mycoplasma pneumoniae IgM antibodies determined by electrochemiluminescence method were elevated $(27$; normal values $<10)$. The patient fulfilled six out of eight criteria for the diagnosis of HLH. She was treated with clarithromycin at $15 \mathrm{mg} / \mathrm{kg} /$ day orally for 10 days and dexamethasone at $10 \mathrm{mg} / \mathrm{m}^{2} /$ day, i.v., for seven days with gradually tapered dosage and supportive therapy (immunoglobulins at $1 \mathrm{~g} / \mathrm{kg}$, platelet transfusion, antimycotic therapy and gastroprotective agents). The fever resolved after three days of treatment with the patient's laboratory findings improving along with normalization of platelet counts after 10 days. The patient was discharged from the hospital after 14 days of treatment and her laboratory findings maintained within normal limits over the next 12 months.

Mycoplasma pneumoniae causes upper and lower respiratory tract infections, known as community-acquired pneumonia. Usually, infections with $M$. pneumoniae are mild and self-limiting, but there are situations when patients develop severe and fulminant disease. M. pneumoniae can also bring about extrapulmonary manifestations, such as: neurological manifestation (encephalitis, meningitis, optic neuritis and Guillain-Barré syndrome), skin manifestations (Stevens-Johnson syndrome and $M$. pneumoniae-associated mucositis), ocular manifestations (conjunctivitis, anterior uveitis, optic neuropathy, retinitis and iritis), cardiac manifestations (heart failure, myocarditis, pericarditis and pericardial effusion), hematological manifestations (hemolytic anemia, aplastic anemia, thrombocytopenic purpura and intravascular coagulation), gastrointestinal manifestations (cholestatic hepatitis and pancreatitis), musculoskeletal manifestations (myalgias, arthralgias and polyarthropathies) and renal manifestations (glomerulonephritis) (6-9).

The association of HLH with $M$. pneumonia infection is rare, though it has been reported in children with pneumonia, usually having a favorable prognosis at this age, but there are also reported cases in adults (table 1). All cases previously reported have originated from Asia and mainly Japan (10-15). The case we presented here is the first patient from Europe.

We established the diagnosis of HLH based on the six of eight criteria: fever, splenomegaly, cytopenia affecting at least two cell lines, hyperferritinemia (ferritin $>500 \mu \mathrm{g} / \mathrm{L}$ ), hypertriglyceridemia $>265 \mathrm{mg} / \mathrm{dL}$ and hemophagocytosis in the bone marrow.

There were at least two criteria that could be interpreted: splenomegaly, which simultaneously with hepatomegaly could be present in patients with severe cardiac malformations, and the concentration of hemoglobin. Splenomegaly was not present before the infection mentioned as determined from regular medical reports of the pediatric cardiologist from the previous two years. The values for hemoglobin in our patient $(10.9 \mathrm{~g} / \mathrm{dL})$ were considered to be significantly reduced as earlier, the patient presented polycythemia (hemoglobin value: $17.8 \mathrm{~g} / \mathrm{dL}$ ) as a result of complex cardiac malformation with secondary severe pulmonary hypertension. The pathogenesis of HLH involves impaired activation of T-lymphocytes that leads to excessive cytokine production (tumor necrosis factor- $\alpha$, IL-1b, IL- 


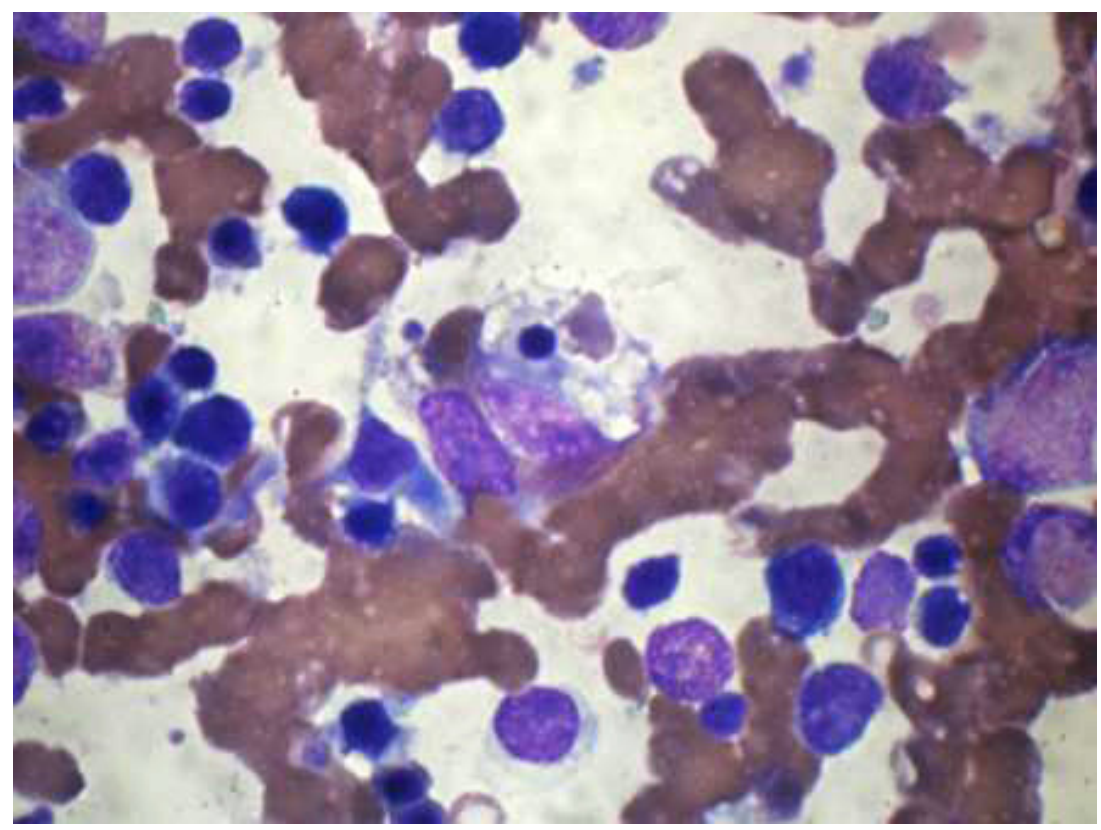

Figure 1. Bone marrow aspirate (HE coloration, magnification $X$ 100): Macrophage with signs of hemophagocytosis, mainly erythrocytes and platelets.

6 , IL-8 and interferon- $\gamma$ ) and infiltration with histiocytes with hemophagocytic activity of the reticuloendothelial systems (including the bone marrow and central nervous system). Infiltration by histiocytes and increasing secretion of cytokines are responsible for the signs and symptoms of HLH and abnormalities in laboratory parameters (1-3). High levels of cytokines also

Table 1. Association of HLH and M. pneumoniae infection in patients of different origin

\begin{tabular}{lcccccc}
\hline $\begin{array}{l}\text { Origin of the } \\
\text { patients }\end{array}$ & $\begin{array}{c}\text { No. of } \\
\text { patients }\end{array}$ & Age & $\begin{array}{c}\text { Days of } \\
\text { fever }\end{array}$ & $\begin{array}{c}\text { Associated } \\
\text { diseases }\end{array}$ & $\begin{array}{c}\text { bone marrow } \\
\text { examination }\end{array}$ & Treatment \\
\hline Japan (10) & 2 & $10-11$ years & 6 & pneumonia & hemophagocytosis & $\begin{array}{c}\text { Erythromicyn } \\
\text { Corticosteroids } \\
\text { Immunoglobulin }\end{array}$ \\
\hline Japan (11) & 4 & $1-11$ years & $7-11$ & pneumonia & hemophagocytosis & $\begin{array}{c}\text { Clarithromicyn } \\
\text { Corticosteroids } \\
\text { Immunoglobulin }\end{array}$ \\
\hline Japan (12) & 1 & 7 years & 6 & pneumonia & no & $\begin{array}{c}\text { Clarithromicyn } \\
\text { Prednisolone }\end{array}$ \\
\hline South Asia (13) & 1 & 28 years & 14 & $\begin{array}{c}\text { pneumonia } \\
\text { Still's disease }\end{array}$ & hemophagocytosis & $\begin{array}{c}\text { Clarithromicyn } \\
\text { Methylprednisolone }\end{array}$ \\
\hline Japan (14) & 1 & 3 years & 4 & pneumonia & hemophagocytosis & $\begin{array}{c}\text { Clarithromicyn } \\
\text { Prednisolone } \\
\text { Immunoglobulin }\end{array}$ \\
\hline Japan (15) & 1 & 30 years & 19 & - & hemophagocytosis & $\begin{array}{c}\text { Clarithromicyn } \\
\text { Prednisolone }\end{array}$ \\
\hline
\end{tabular}


have an important role in the development of extrapulmonary manifestations in $M$. pneumoniae infection and the level of IL-18 is greater in patients with severe forms of the infection as well as exhibiting a positive correlation with $\mathrm{LDH}$ levels (16). M. pneumoniae may determine transient depression of T-lymphocyte function and depletion of CD4+ T-cells. On the other hand, the cell-mediated immunity of the host is related to the progression and severity of M. pneumoniae infection and patients with Down syndrome could have a higher risk for severe infection course based on the previously described immune defects, such as T- and B-cell lymphopenia, impaired mitogen-induced T-cell proliferation and compromised neutrophil chemotaxis (9, 17). Another factor that could be considered as predisposing for severe course of infection is the presence of pulmonary hypertension secondary to the cardiac malformation. Treatment administered consisted of antibiotics, corticosteroids and immunoglobulins; platelet transfusion was also effective with progressive normalization of laboratory parameters and disappearance of symptoms.

In conclusion, HLH could be a complication of $M$. pneumoniae infection under certain conditions. In case of antibiotics refractory pulmonary infections, HLH should always be considered and treatment would best commence as soon as possible.

\section{Cecilia Lazea $^{1^{*}}$, Cristina Blag ${ }^{2}$}

\section{University of Medicine and Pharmacy, Department Pediatrics 1, Cluj-Napoca, Romania}

2. University of Medicine and Pharmacy, Department Pediatrics 2, Cluj-Napoca, Romania

\section{Corresponding author}

Cecilia Lazea, e-mail: cicilazearo@yahoo.com
Received: $5^{\text {th }}$ August 2017

Accepted: 20 ${ }^{\text {th }}$ November 2017

Published: $9^{\text {th }}$ December 2017

\section{Conflicts of interest}

The authors declare no conflicts of interest.

\section{References}

1. George MR. Hemophagocytic lymphohistiocytosis: review of etiologies and management. J Blood Med. 2014 Jun;5:69-86. DOI: 10.2147/JBM.S46255

2. Ishii E. Hemophagocytic Lymphohistiocytosis in Children: Pathogenesis and Treatment. Front Pediatr. 2016 May;4:47. DOI: 10.3389/fped.2016.00047

3. Malinowska I, Machaczka M, Popko K, Siwicka A, Salamonowicz M, Nasiłowska-Adamska B. Hemophagocytic syndrome in children and adults. Arch Immunol Ther Exp (Warsz). 2014 Oct;62(5):385-94. DOI: $10.1007 / \mathrm{s} 00005-014-0274-1$

4. Cetica V, Sieni E, Pende D, Danesino C, De Fusco C, Locatelli $\mathrm{F}$ et al. Genetic predisposition to hemophagocytic lymphohistiocytosis: Report on 500 patients from the Italian registry. J Allergy Clin Immunol. 2016 Jan;137(1):188-96.e4. DOI: 10.1016/j.jaci.2015.06.048

5. Henter JI, Horne A, Aricó M, Egeler RM, Filipovich $\mathrm{AH}$, Imashuku S, et al. HLH-2004: Diagnostic and therapeutic guidelines for hemophagocytic lymphohistiocytosis. Pediatr Blood Cancer. 2007 Feb;48(2):12431. DOI: $10.1002 /$ pbc. 21039

6. Parrott GL, Kinjo T, Fujita J. A Compendium for Mycoplasma pneumoniae. Front Microbiol. 2016 Apr; 7:513. DOI: $10.3389 /$ fmicb.2016.00513

7. Meyer Sauteur PM, Unger WW, Nadal D, Berger C, Vink C, van Rossum AM. Infection with and Carriage of Mycoplasma pneumoniae in Children. Front Microbiol. 2016 Mar;7:329. DOI: 10.3389/fmicb.2016.00329

8. Vervloet LA, Marguet C, Camargos PA. Infection by Mycoplasma pneumoniae and its importance as an etiological agent in childhood community-acquired pneumonias. Braz J Infect Dis. 2007 Oct;11(5):507-14. DOI: $10.1590 /$ S1413-86702007000500012

9. Waites KB, Talkington DF. Mycoplasma pneumoniae and its role as a human pathogen. Clin Microbiol Rev. 2004 Oct;17(4):697-728. DOI: 10.1128/ CMR.17.4.697-728.2004

10. Ishida Y, Hiroi K, Tauchi H, Oto Y, Tokuda K, Kida K. Hemophagocytic lymphohistiocytosis secondary to Mycoplasma pneumoniae infection. Pediatr Int. 2004 Apr; 46(2): 174-7. DOI: 10.1046/j.1442-200x.2004.01878.x 
11. Yoshiyama M, Kounami S, Nakayama K, Aoyagi N, Yoshikawa N. Clinical assessment of Mycoplasma pneumoniae associated haemophagocytic lymphohistiocytosis. Pediatr Int. 2008 Aug; 50(4): 432-5. DOI: 10.1111/j.1442-200X.2008.02701.x

12. Koike Y, Aoki N. Hemophagocytic Syndrome Associated with Mycoplasma pneumoniae Pneumonia. Case Rep Pediatr. 2013 Jul; 2013: 586705.

13. Agnihotri A, Ruff A, Gotterer L, Walker A, McKenney AH, Brateanu A. Adult Onset Still's Associated with Mycoplasma pneumoniae Infection and Hemophagocytic Lymphohistiocytosis. Case Rep Med. 2016 Oct;2016:2071815.

14. Yasutomi M, Okazaki S, Hata I, Tanizawa A, Tamamura S, Kawakita M, Ohshima Y. Cytokine profiles in Mycoplasma pneumoniae infection-associated hemophago- cytic lymphohistiocytosis. J Microbiol Immunol Infect. 2016 Oct;49:813-6. DOI: 10.1016/j.jmii.2014.11.015

15. Hibino M, Sato S, Shimizu T, Yamamoto S, Ohe M, Kondo T. Hemophagocytic Lymphohistiocytosis Secondary to Mycoplasma pneumoniae infection without pneumonia. Intern Med. 2014 Aug;53(15):1679-83. DOI: 10.2169/internalmedicine.53.2089

16. Miyashita N, Kawai Y, Inamura N, Tanaka T, Akaike H, Teranishi $\mathrm{H}$, et al. Setting a standard for the initiation of steroid therapy in refractory or severe Mycoplasma pneumoniae pneumonia in adolescents and adults. J Infect Chemother. 2015 Mar; 21(3):153-60. DOI: 10.1016/j.jiac.2014.10.008

17. Ram G, Chinen J. Infections and immunodeficiency in Down syndrome. Clin Exp Immunol. 2011 Apr;164(1): 9-16. DOI: 10.1111/j.1365-2249.2011.04335.x 